See Article page 289.

\section{Commentary: Do you have any doctors in your family?}

\author{
Jarvis C. Mays, BA, ${ }^{a}$ and Jason J. Han, MD ${ }^{\mathrm{b}}$
}

Study after study continues to demonstrate that increasing diversity among medical professionals improves patient outcomes. As a result, national organizations, medical schools, and training programs are endeavoring to improve representation, particularly regarding the recruitment of women and members of underrepresented minorities in medicine. Furthermore, our approach to defining privilege or the lack thereof continues to become more holistic and nuanced. In addition to sex and race, other socioeconomic considerations such as being an immigrant, international medical graduate, or first-generation applicant are being explored.

Robinson and Do-Nguyen ${ }^{1}$ describe firsthand the struggles first-generation medical students may face along their path to becoming cardiothoracic surgeons. The authors initially emphasize how the lack of a consistent definition of first-generation medical student has made it difficult to identify those in need of extra resources such as mentorship, financial support, and early exposure to competitive fields within medicine. They propose a definition of students whose parents have not earned a postsecondary undergraduate degree (eg, associates, bachelors, masters, or doctoral degree). Based on this definition, first-generation medical students represent up to $20 \%$ of medical students, half of whom are members of underrepresented minority groups.

The authors note that it may be more difficult for these students to gain exposure to specialties like cardiothoracic surgery early on given fewer connections and resources. Moreover, given the highly competitive and demanding

\footnotetext{
From the ${ }^{\mathrm{a}}$ Perelman School of Medicine and ${ }^{\mathrm{b}}$ Division of Cardiovascular Surgery, Department of Surgery, Hospital of the University of Pennsylvania, Philadelphia, $\mathrm{Pa}$.

Disclosures: The authors reported no conflicts of interest.

The Journal policy requires editors and reviewers to disclose conflicts of interest and to decline handling or reviewing manuscripts for which they may have a conflict of interest. The editors and reviewers of this article have no conflicts of interest.

Received for publication July 11, 2021; revisions received July 11, 2021; accepted for publication July 16, 2021; available ahead of print Aug 2, 2021.

Address for reprints: Jason J. Han, MD, Division of Cardiovascular Surgery, Department of Surgery, Hospital of the University of Pennsylvania, 3400 Spruce St, 6 Silverstein Pavilion, Philadelphia, PA (E-mail: Jason.Han@ pennmedicine.upenn.edu).

JTCVS Open 2021;7:294

2666-2736

Copyright (C) 2021 The Author(s). Published by Elsevier Inc. on behalf of The American Association for Thoracic Surgery. This is an open access article under the CC BY-NC-ND license (http://creativecommons.org/licenses/by-nc-nd/4.0/). https://doi.org/10.1016/j.xjon.2021.07.016
}

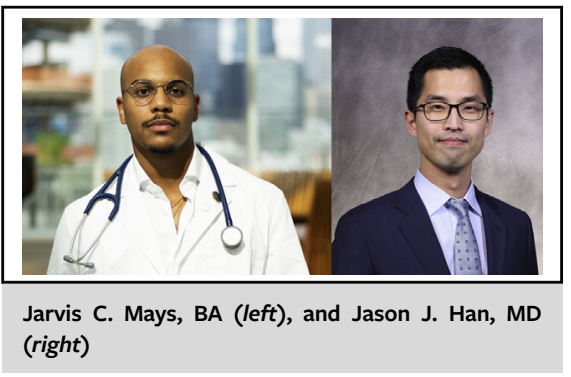

CENTRAL MESSAGE

It is important for the field of cardiothoracic surgery to understand and recognize the perspectives of current and future first-generation aspiring surgeons to best support them.

nature of the specialty, the financial burden of attending medical school, arranging multiple away rotations, and applying to and interviewing at a high number of residency programs can prove to be a substantial barrier to entry. Combined with the fact that these students are more likely to come from homes with lower parental income, they may experience increased disadvantages, stress, and fatigue.

Recruiting a highly qualified and diverse group of students remains a priority in the field of cardiothoracic surgery. In addition to varied backgrounds, they offer enhanced resilience, emotional intelligence, critical thinking ability, and problem-solving doggedness, all of which are characteristics often seen in successful cardiothoracic surgeons.

We congratulate the authors on their thoughtful descriptions and recommendations. Better defining the characteristics and needs of this population, creating scholarship opportunities, adopting a more holistic approach to reviewing applicants, and forming national committees aimed at enrichment of this population are important starting points. As we go forward, it is imperative that the field of cardiothoracic surgery continues to acknowledge these diverse perspectives and take steps to ensure equal opportunities for all of its members for the betterment of our community, and especially for our patients.

\section{Reference}

1. Robinson JA, Do-Nguyen CC. Increasing diversity in cardiothoracic surgery: first-generation medical students. J Thorac Cardiovasc Surg Open. 2021;7: 289-93. 